\title{
Die Tagebücher
}

von

\section{Joseph Goebbels}





\title{
Die Tagebücher
}

\section{VOn}

\section{Joseph Goebbels}

\section{Im Auftrag des Instituts für Zeitgeschichte}

und mit Unterstützung des Staatlichen Archivdienstes Rußlands

Herausgegeben von Elke Fröhlich

\author{
Teil II \\ Diktate 1941-1945 \\ Band 8 \\ April-Juni 1943
}

Bearbeitet von Hartmut Mehringer

$\mathrm{K} \cdot \mathrm{G} \cdot$ Saur

München $\cdot$ New Providence $\cdot$ London $\cdot$ Paris

1993 
Die Deutsche Bibliothek - CIP-Einheitsaufnahme

Goebbels, Joseph:

Die Tagebücher / von Joseph Goebbels.

Im Auftr. des Instituts für Zeitgeschichte hrsg. von Elke Fröhlich. -

München ; New Providence ; London ; Paris : Saur.

ISBN 3-598-21920-2

NE: Fröhlich, Elke [Hrsg.]; Goebbels, Joseph: [Sammlung]

Bd. 8: Teil 2, Diktate 1941 - 1945. April - Juni 1943 / bearb.

von Hartmut Mehringer. - 1993

ISBN 3-598-22304-8

NE: Mehringer, Hartmut [Bearb.]

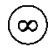

Gedruckt auf säurefreiem Papier

Printed on acid-free paper

Alle Rechte vorbehalten / All Rights Strictly Reserved

K.G. Saur Verlag, München 1993

A Reed Reference Publishing Company

Druck/Binden: Graphische Kunstanstalt Jos. C. Huber, Dießen/Ammersee

ISBN 3-598-21920-2 (Teil II)

ISBN 3-598-22304-8 (Band 8) 